\title{
Management Innovation and Dynamic Mechanism in Software Outsourcing Industry
}

\author{
Qiang DING ${ }^{1, a}$ \\ ${ }^{1}$ Suzhou Industrial Park Institute of Services Outsourcing, Suzhou, 215123, China
}

Keywords: Software Outsourcing; Enterprise Management; Innovation; Dynamic Mechanism

\begin{abstract}
As an emerging industry sector, software and information services outsourcing industry has an increasingly broader market in the background of the information age. Since the second decade of the $21^{\text {st }}$ century, the fourth technological revolution, taking cloud computing and networking as the representatives, has continuously promoted the development of informatization in depth direction, and such change is not only reflected in the development way of software, but more importantly in the fact that the boundary between software and the services of software and information has been gradually indistinct. There are thousands of professional software talents in Jiangsu every year, to provide a large number of human resources for the software and information industry; under the strong support of the government and local enterprises, Jiangsu's software and the information and technology services outsourcing industry has been developed into a considerable scale, having entered the stage of rapid development from the initial stage, while it still needs to be further improved in the industrial structure and other aspects, including the export-oriented degree of the industry and the relatively low industrial level, bottleneck of the software and service outsourcing talents and other factors are still the biggest bottleneck of restricting the development of BPO industry.
\end{abstract}

\section{Introduction}

Since 1990s, the old industrial cities in the coastal areas are faced with the challenge of transferring from the traditional heavy industry city into the comprehensive service city, and there mainly are two ways to transfer: the first way is to vigorously promote the research and development of science and technology, so as to promote the comprehensive development of the emerging industry, which is mainly about the high technology; the second way is to vigorously develop the informatization service industry, to promote the comprehensive upgrading and rebuilding of traditional industries with informatization, with the international modern management concept as the core, to provide more efficient industry environment for industrial upgrading and industrialization as well as independent innovation.

As Suzhou is an eastern coastal city, the software and information service outsourcing industry in Suzhou, although started late, has powerful developing momentum, especially in July of 2008, when the three ministries, namely Ministry of Commerce, Ministry of Industry and Information Technology, Ministry of Science and Technology, officially appointed Suzhou City as the service outsourcing base city in China, indicating that the development of software and information service outsourcing industry in Suzhou entering a new developing stage; Suzhou is in the eastern development area, so the software and information service outsourcing industry has been benefiting from national policy; relying on preferential investment industrial environment, a large number of strong domestic and foreign software companies have settled in Suzhou in succession, making significant contribution to the development of Suzhou's software industry. According to data released by Suzhou Economic and Information Commission, in 2014, the annual revenue of the software and information service industry in Suzhou had the year-on-year growth of 26\%, reaching RMB135.1 billion, accounting for $26.8 \%$ of the electronic information industry scale for the whole city, among which the software business revenue reached RMB 73.65 billion, with the year-on-year growth of $27.36 \%$, and was $7.1 \%$ higher than the national average level.

After 2010, acquisition and reorganization between enterprises have been increasingly fierce in 
the software industry, which, on the one hand, promotes the growth of the software and information service outsourcing industry, strengthens the trend of networking and specialization, and forms the highlights of high-end and personalized service industry, while on the other hand, the export-oriented degree of the industry and the relatively low industrial level, the insufficient scale of the industry, and the low competitiveness in Suzhou seriously hinder Suzhou's software industry from participating in international market competition, which is not conducive to the development of Suzhou's software industry.

Since 2014, the economic situation at home and abroad, although in certain recovery, has faced a variety of uncertainties and the global economy has been under a lot of downward pressure, which will increase the difficulty for Suzhou software and information service outsourcing industry in expanding the domestic and international market, and there is a weakening risk in the development trend of software and information services industry. However, at the same time, the development of software industry also has a lot of rare opportunities, such as the accelerated information technology investment, strong demand for information consumption, accelerated transformation of software services, strong momentum of development in emerging areas and other important development opportunities, which are likely to provide opportunities for the software and information services industry to achieve contrarian growth.

\section{Analysis of the Software and Information Services Outsourcing}

\section{International background for software and information service outsourcing industry}

Till 1970s and 1980s, the third technological revolution led by the information and technology has been developing rapidly, to inject new vitality into the development of world economy. In the 21st century, information and technology is developing more rapidly, with huge information and technology market; according to Gartner's latest research, the total global software market revenue in 2013 reached $\$ 407.3$ billion, with an increase of 4.8\% compared to \$388.5 billion in 2012.

Global information and technology outsourcing grow strongly. According to Gartner's latest research report, the expenditure for global information and technology outsourcing in 2014 reached nearly \$300 billion, with the compound annual growth rate up to 3.8\% in the next five years, so it is estimated accordingly that the global information and technology service outsourcing will outbreak the gap of $\$ 300$ billion in 2016.

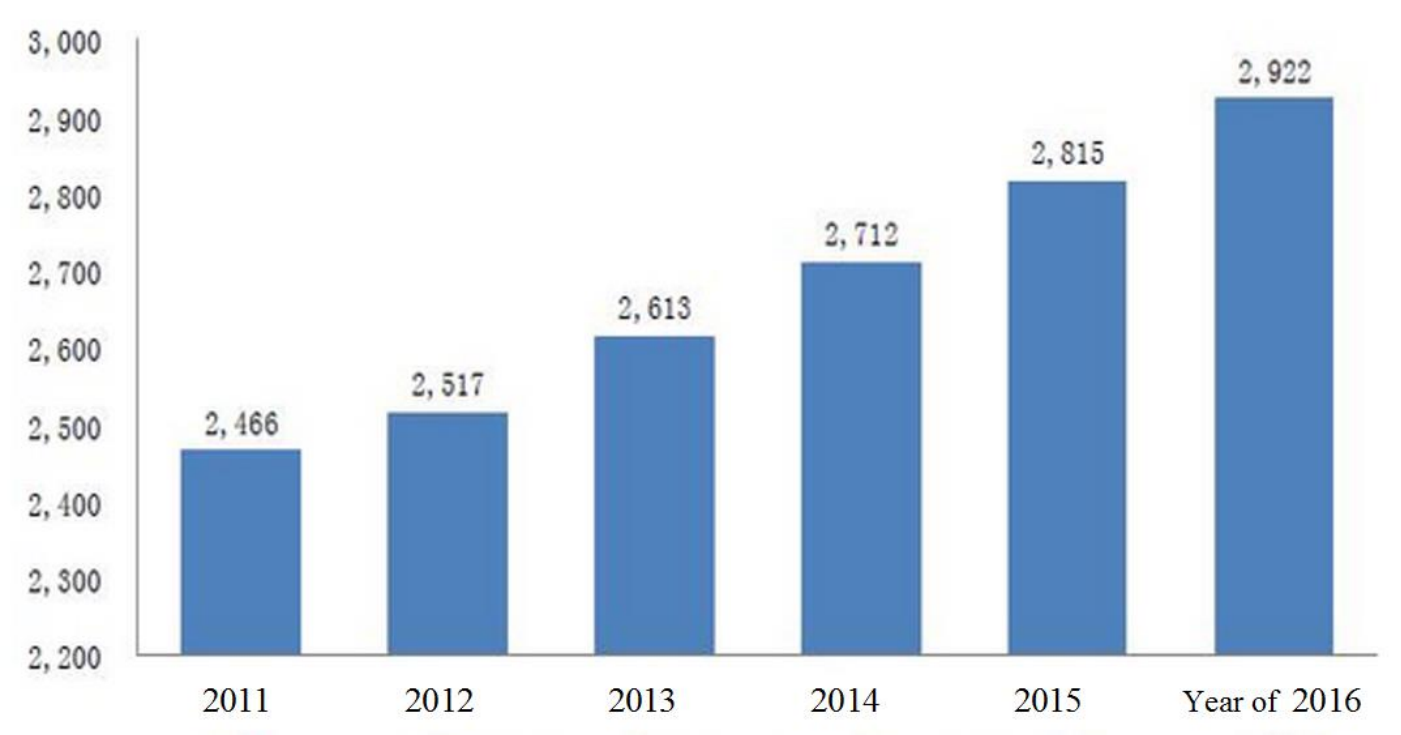

Fig. 1. Expenditure scale for global information and technology outsourcing

Global offshore service outsourcing develops rapidly. As early as in 2011, the market scale of global offshore service outsourcing has reached $\$ 1000$ billion, and in recent years, the compound annual growth rate of global offshore service outsourcing has been maintained for more than 18\%, expected to reach the scale of \$2000 billion in 2015. 


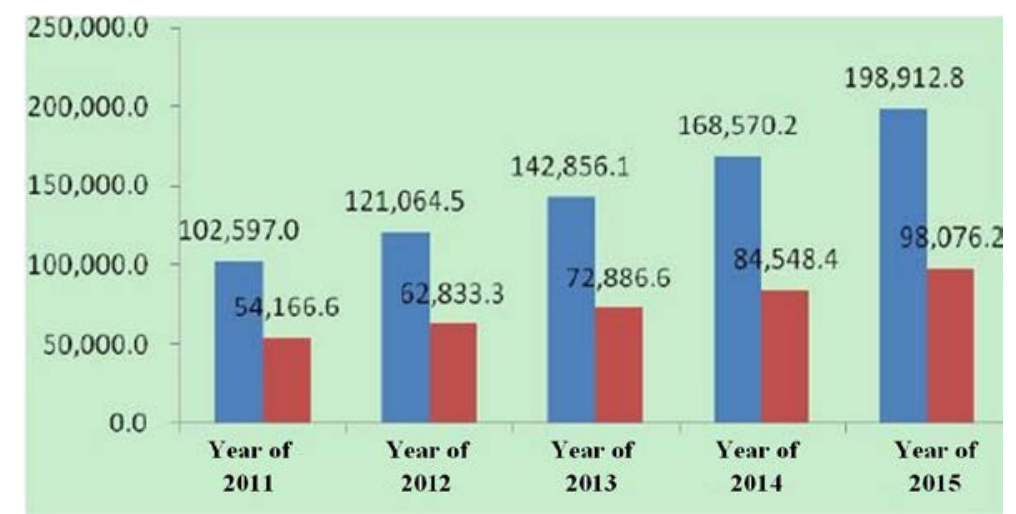

Fig. 2. Scale of global offshore service outsourcing (the red represents the scale of it service)

Global software and information services industry transfer. The contracting countries are the developed countries led by United States, Japan and the Europe, in which the United States is the main contracting country, while the emerging economies, led by BRIC countries, are the main undertaking countries. Under this situation, the service outsourcing of developed countries is not dominant, and the global software and information service outsourcing industry has entered a totally new developing trend.

\section{Background for domestic software and information service outsourcing industry}

Since the financial crisis in 2008, although the international economic situation has been quite complicated, the domestic software and information service outsourcing industry still remains in a strong developing trend, with the steady expansion of industrial scale and industrial growth maintained in the leading situation, while the international status has risen steadily.

A few days ago, the Coordination Bureau of the Ministry of Industry and Information Technology issued the annual report of 2014 electronic information industry statistics in China, and the annual report pointed out that the scale of China's electronic information industry is expanding, while the proportion of the software industry has continued to improve, with the rate of $26.6 \%$, 1.6\% higher than that of 2013.

In 2014, China had more than 38000 software and information services enterprises, and the cumulative total annual sales revenue reached RMB 14 trillion, with the year-on-year growth of $13 \%$ than 2013. Where, software and information services industry reached the revenue of RMB 3.7 trillion, with the year-on-year growth of $20.2 \%$. In the field of electronic information industry enterprise, in 2014 the number of enterprises above scale was more than 50000, of which there were more than 18700 electronic information manufacturing enterprises.

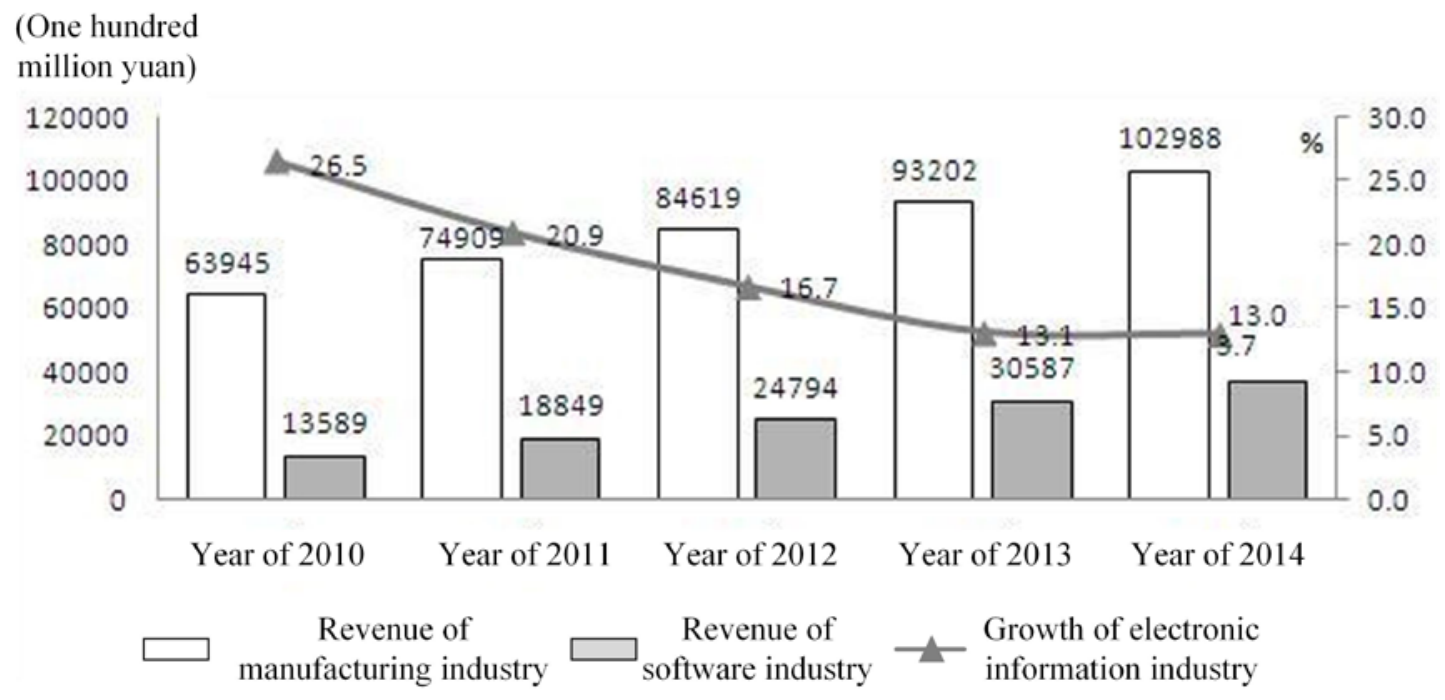

Fig. 3. China's electronic industry growth in 2010-2014

Domestic software and information service has made and achieved some achievements of development, still there are the following problems:

1 Relatively small enterprise scale; similar to China's existing high-tech industries, software and 
information service outsourcing started late in China, hard to avoid the embarrassment of small enterprise scale, low market share and lack of talent.

2 Insufficient research and development funds; due to the lack of independent research and development funds, domestic software companies mainly rely on the introduction and imitation of international advanced products. Lacking of research and development capability is destined to lead to the lack of core competitiveness, let along their delivery center, so they often play the role of local service providers and regional service providers in the international market, in a relatively low stage.

3 Low-end business and low quality of service; projects undertaken by China's software and information service outsourcing enterprises mostly belong to the international low-end business, while in IT consulting industry, applications system outsourcing service industry and other aspects with higher-end business, most of the current domestic software and information service outsourcing enterprises obviously lack of capacity, not able to provide the corresponding high-level service.

4 Unreasonable structure of talents and the relatively weak training and management of talents; first of all, China's software and information service talent structure is irrational, relatively short of high-level talent in the software industry, and the middle-class talents, such as systems engineer, is relatively redundant; secondly, compound talents are insufficient. Expect for a small number of returned students, the technical management personnel in China's software industry are generally poor in English, lacking of compound talents that are capable of language, technology and management.

5 Non-standardized industry standards, relative lagging. The monitoring for the quality and contract of service outsourcing is not complete, and the software companies are focused on their own work and prepare the standards for their own situation, lacking of international standards and norms for software development, thus leading to the situation that software development does not have the norm for reference.

6 Relevant laws and policies supporting measures need to be improved. At present, the legal environment of China's service outsourcing is not perfect, especially the information security, intellectual property legislation, intellectual property protection policies and related supporting measures, with relatively lighter penalties for behaviors violating information security. These factors affect the international image of China's software industry, and affect the contracting will of the international contracting countries.

\section{Development Direction and Suggestion}

\section{Adhering to the principle of industrial agglomeration}

Focus on the planning of the information industry park, and vigorously develop the infrastructure and the related supporting facilities matched with the information industry. Actively guide the relevant industries to gather to the information industry park, and vigorously guide and cultivate large leading enterprises and core based industries, to promote the steady development of the downstream enterprise chain.

\section{Adhering to market-oriented principle of expanding the opening to the outside world}

For the development of the information industry, the government should act as a guiding role, act as an active middleman, formulate appropriate development policies, and create a favorable environment for development; take the industrial market as the leading, open the market, seize the major opportunities brought by the international and domestic information industry structure adjustment and transformation, with the information core industry park as the carrier, actively carry out effective technology introduction, and make full use of the rich resources inside and outside the market, to promote the development in variable forms of software and information service industry.

Adhering to the principle of independent innovation and development of science and technology

The continuous maturity of software and information service industry will inevitably lead to the transferring of the development advantage from the cost advantage to the technical advantages 
based on independent innovation. The development of software and information service outsourcing industry in Chongqing must change from the traditional location cost advantage to the more competitive technical advantage. Improve the ability of independent innovation in key areas and key technologies, actively introduce international advanced management and production technology, and combine with each other to enhance the core competitiveness of the industry.

Adhering to the principle of overall planning, all-around consideration and coordinated development

While actively developing the software and information service outsourcing industry, we should pay attention to the coordinated development between industries related to the information industry, the coordinated development between the information industry and other industries, as well as the coordinated development between Chongqing base and other national information industry base, to highlight the characteristic construction of base.

\section{References}

[1] Chen J, Zeng S, Zheng Z. Notice of Retraction Innovation Oriented Selection for Shanghai Business Process Outsourcing Industry[C]// International Conference on Wireless Communications, NETWORKING and Mobile Computing. IEEE, 2007:6361-6364.

[2] Yang D. The Effect of Knowledge Management on Product Innovation - Evidence from the Chinese Software Outsourcing Vendors[J]. Ibusiness, 2011, 3(1):16-22.

[3] Li S C, Lai H L, Hu Y S. Notice of Retraction Analysis on the dynamic mechanism of R \& D industry[C]// International Conference on E -Business and E -Government. IEEE, 2011:1-4.

[4] Lacity M, Willcocks L. Business process outsourcing and dynamic innovation[J]. Strategic Outsourcing, 2014, 7(1):66-92(27).

[5] Wang R, Chen Q. Analysis and Research on Dynamic Mechanism of Knowledge Intensive Business Service Innovation Cluster[J]. Advances in Information Sciences \& Service Sciences, 2012, 4(21):15-22. 